\title{
Using Gis Tools to Support E_Participation - A Systematic Evaluation
}

\author{
Euripidis Loukis ${ }^{1}$, Alexander Xenakis ${ }^{2}$, Rob Peters $^{3}$, and Yannis Charalabidis ${ }^{1}$ \\ ${ }^{1}$ University of the Aegean, Gorgyras Str., Karlovassi 83200, Greece \\ \{eloukis,yannisx\} @ aegean.gr \\ ${ }^{2}$ Panteion University, Syggrou Avenue 136, Athens 17672, Greece \\ a.xenakis@panteion.gr \\ ${ }^{3}$ Zenc BV, Alexanderstraat 18, Den Haag 2514 JM, Netherlands \\ rob.peters@zenc.n1
}

\begin{abstract}
In this paper a systematic evaluation is presented of an e-participation platform based on GIS tools. The evaluation methodology is founded on the Technology Acceptance Model (TAM), which has been elaborated and adapted to this particular type of IS, taking into account the particular objectives and capabilities of this platform. Our main evaluation dimensions were usage, ease of use, functional usefulness, political usefulness and importance of discussion topic; each of them has been analyzed into a number of sub-dimensions. Using this methodology five pilot applications of this platform in 'real-life' situations and problems have been evaluated with both quantitative and qualitative techniques. Finally it has been concluded that the use of GIS tools can provide significant value in the area of e-participation, which however depends on a number of context factors, such as citizens' computer literacy and familiarization, trust to the political system, interest of the sponsoring public authorities, appropriate promotion, importance of the topic under discussion and quantity and quality of reference information appended on the digital maps by public authorities.
\end{abstract}

Keywords: geographical information systems (GIS), e-participation, evaluation, technology acceptance model (TAM).

\section{Introduction}

A relatively new concept in the area of e-participation is the use of digital maps and geographic information systems (GIS) for supporting and enhancing on-line deliberations, by offering to the participants the capability to upload and access geographically referenced multimedia content concerning various aspects of the topics under discussion, especially with regard to spatial planning, environmental and energy issues [1] - [2]. Though there has been some previous literature concerning the use of GIS in the area of e-participation, which is briefly reviewed later in section 2 , there is a lack of systematic evaluations of such efforts, based on sound theoretical 
foundations, which would provide more complete and reliable conclusions about the potential of GIS in e-participation and the context factors affecting it.

This paper contributes to filling this research gap by presenting a systematic evaluation of an e-participation platform based on GIS tools, which has been developed as part of the FEED project (www.feed-project.eu) co-financed by the European Commission under its e-Participation Initiative. This project aimed at improving the quality of implementation of European legal acts concerning energy and environment by enabling enhanced maps/GIS-based interaction between regional/local government and citizens. For achieving these objectives an advanced eparticipation platform was developed, which allows citizens and government organizations to share quickly and easily multimedia content they have generated themselves (e.g. a picture or video produced even through a simple mobile phone, which shows a problem or documents an opinion/position concerning in a particular geographical location or area) through a map interface [1] - [2]. Every user of this platform (citizen or public organization) can upload multimedia documents on the topic under discussion and associate it with a particular geographical location or area, and also search (using the digital map or/and the semantic annotation of all documents) for relevant content provided by other citizens or public administrations. Beyond this powerful interaction mechanism, the platform offers additional interaction capabilities through forum and petition functionalities. These capabilities were expected to result in a significant improvement of the quantity and quality of interaction among citizens, and also with public administrations, concerning the formulation of public policies and decisions.

In the following sections we present the evaluation of five 'real-life' pilot applications of this platform in five quite different national contexts (Greece, Czech Republic, Slovakia, UK and Netherlands) as part of the FEED project. In section 2 we provide a brief review of previous literature on the use of GIS for supporting public participation, while in section 3 we describe the evaluation methodology. Section 4 presents the main results from the evaluation of each pilot application, while in section 5 results are discussed and final conclusions are drawn.

\section{Background}

In the pertinent literature it has been recognized that GIS have a great potential in the area of e-participation for supporting resolution of conflict among stakeholders concerning various public policies, and assisting in reaching decisions that are acceptable to the majority of them, through consensus-building approaches based on awareness of the spatial dimensions and implications of problems (e.g. [3]). GIS can present maps with different layers and also perform various spatial analyses based on them. However, it has been argued that GIS technology itself is highly complex, so it can be effectively used mainly by specialists. In [4] it is argued that an integration of maps and multi-criteria decision making tools through data visualization can improve the understanding of decision situations, and lead to better outcomes of the decision making process; the authors propose to achieve such integration through an interactive and dynamic visualization of criteria and decision spaces. Nonetheless, it is noted that we need to approach GIS as a socially constructed technology, including 
not just hardware and software but also practice, laws, organizational arrangements, and knowledge which are necessary for its use [5].

Public Participatory Geographical Information Systems (PP GIS) is a research area that focuses on the exploitation of GIS by the general public supporting their participation in government decision-making processes. Its main objective is to expand the use of GIS to the general public and non-governmental organizations that are not usually represented in traditional top-down GIS projects [6], [7]. In recent years, applications supporting Public Participatory GIS increasingly use the Internet as a platform for communication and dissemination of information [8]. These applications range from Internet-based spatial multimedia systems to conventional field-based participatory development methods with a modest GIS component. However, there is a lack of systematic evaluations of such Public Participatory GIS, based on sound theoretical foundations. The abovementioned FEED platform is an example of such a Public Participatory GIS, and in the following sections we are describing the systematic evaluation of it, contributing to filling this research gap.

\section{Evaluation Methodology}

For evaluating the five pilot applications of this advanced e-participation platform a methodology was formulated based on the Technology Acceptance Model (TAM), which provides a mature and well established framework for evaluating IS [9] - [13]. Therefore our main evaluation dimensions were usage, ease of use and usefulness. Each of them was further elaborated and adapted to the objectives, capabilities and specificities of this platform. In particular:

I) The usage of the platform was evaluated by assessing the extent of using it for getting information on the topic under discussion and for contributing postings about it in the forum.

II) The ease of use was evaluated by assessing how easy it was for the users to use the platform in general and also its the main capabilities: to search for and find information using the map, to access the postings of the other users or add a new posting.

III) The usefulness dimension, taking into account that a user of such a platform has both functional objectives (e.g. read information and postings on the topic under discussion, and enter his/her own contributions) and political objectives (influence decisions and public policies on the topic under discussion), was divided into subdimensions: the 'functional usefulness' and the 'political usefulness'. The former was evaluated by assessing to what extend the users find that the map interface and the information uploaded on it enabled them to get better informed on the topic under discussion and to contribute more informed postings in the forum discussion, and also to what extend the forum postings of others increased their knowledge on the discussion topic. The latter was evaluated by assessing what level of e-participation the users believe that was achieved (using the classification proposed by OECD [14] [15]): one-dimensional information provision from government to citizens, consultation with citizens (aiming at simply collecting their opinions), engagement (meant as consultation affecting government decisions) and citizens' empowering), and whether they believe that the visions and ideas they entered in the forum will be 
further considered by the government, and also their general satisfaction. Furthermore, taking into account that the value for the citizens of the e-consultations conducted through the platform depends also on the importance of the discussion topics, we used it as an additional evaluation sub-dimension. It was evaluated by assessing how important the users find the topics of the electronic discussions, and also to what extent they attract the users to use the platform again in the future.

Each of the above evaluation dimensions was assessed using both quantitative and qualitative techniques. The quantitative evaluation involved the distribution of questionnaires to the users of the platform in the each of the five different pilots deployed. The questionnaire included an initial section with questions concerning respondent's demographic data (concerning age, sex and education), followed by four sections corresponding to the above evaluation dimensions (usage, ease of use, functional and political usefulness and discussion topics). We received an average of 40 filled questionnaires per pilot, with exception of the Dutch pilot, for which a different evaluation approach was adopted, as explained below.

Additionally the responsible partner for each pilot organized a qualitative in-depth discussion in a small focus group of 4-5 persons (participants in the e-consultation and employees of the corresponding sponsoring public organization). The objective of these discussions was to understand in more depth than through the questionnaire what these persons see as main strengths weaknesses of the platform with respect to ease of use and usefulness. The main topics of these in-depth discussions were:

- Ease of use (what is the general impression of these persons concerning the easeof-use of the platform, what functionalities they found easy-to-use, and what functionalities they found difficult-to-use, etc.).

- Functional usefulness (how useful they find the platform for getting information about the topic under discussion, for discussing about with other people and government, for learning new things from them, or other benefits it offers).

- Political usefulness (what the level of influence they believe can be achieved on government decisions about the topic under discussion).

- Importance of the topic under discussion

The structure of the evaluation methodology is summarised below in Table 1 .

Table 1. Structure of the evaluation methodology

\begin{tabular}{|c|c|c|c|c|c|c|}
\hline & $\begin{array}{l}\text { Demo- } \\
\text { graphics }\end{array}$ & Usage & Ease of Use & $\begin{array}{l}\text { Functional } \\
\text { Usefulness }\end{array}$ & $\begin{array}{l}\text { Political } \\
\text { Usefulness }\end{array}$ & $\begin{array}{l}\text { Topics } \\
\text { Importance }\end{array}$ \\
\hline Quantitative & + & + & + & + & + & + \\
\hline Qualitative & & & + & + & + & + \\
\hline
\end{tabular}

Especially for the Dutch pilot application, which, as described in more detailed in 4.5 was the most sophisticated one and concerned some complex, critical and highly controversial decisions about the future of the Amsterdam region (associated with the development or not of new infrastructure and houses in a formerly 'green' area in Jmeer/Markermeer), a different and more detailed evaluation approach was adopted. In particular, all the capabilities of the platform (including both functionality and 
data) were presented in detail to 21 representatives of the main conflicting stakeholders (e.g. chambers of commerce, national government, regional government, building companies, non-government organizations, local community activist organisations), both the ones in favour and the ones against these new developments, who were then asked to evaluate through a questionnaire several usefulness and effectiveness related aspects of the platform. For this particular pilot we performed a more detailed analysis of the usefulness and effectiveness evaluation dimensions into several sub-dimensions, which reflect the particular characteristics of this situation and objectives of this pilot. These 'high-level' representatives of stakeholders had a very limited experience of using the platform themselves, so it was meaningless to ask them to evaluate its ease-of-use; at the same time the discussion topic was definitely of high importance, so there was no reason for asking these persons to evaluate its importance. For these reasons we decided to focus the evaluation of this pilot on a wide range of usefulness/effectiveness-related aspects of the platform.

In particular, these stakeholders were asked after the detailed presentation of the platform to assess initially through a questionnaire, and then in an in-depth qualitative discussion, to what extent it can assist them in the following basic aspects:

- keep track of the complex discussions taking place on these critical issues/questions,

- inform their constituency (i.e. the citizens they represent),

- understand relevant legislation and legal constraints,

- have more transparency in decision making,

- express and support the arguments of the stakeholder groups they represent,

- influence decision making,

- achieve consensus among conflicting groups and reduce the risk of ending up in a legal court,

- and finally have a better spatial planning process.

\section{Evaluation Results}

This section outlines the main results of platform evaluation in five pilot applications of it in 'real-life' situations and problems in five quite different national contexts (Greece, Czech Republic, Slovakia, UK and Netherlands), which were conducted as part of the FEED project.

\subsection{The Greek Pilot Application}

The Greek pilot application took place in the Municipality of Ano Liossia, which is a suburb in the north-western part of Athens, with a population of 26,500. The area has grown rapidly over the last 20 years. Its main problem is that it hosts the largest rubbish dump of Greece, which is currently serving about 4.5 million citizens of the greater Athens area, and is considered a severe danger for the environment and the public health. A considerable proportion of its citizens have low income, education and computer literacy.

The pilot included a public deliberation process supported by the platform about three important topics for Ano Liossia: a)The City Development Plan, which 
constitutes the main proposal of the local Municipality for the development of the area in the next five years; among others, it refers to urban planning, use of renewable energy sources and environmental protection. b)The Municipal City Park, which is being planned and discussed for almost a decade, however without any specific action taken up yet; it is a highly debated issue, as far as its place, size and specifications are concerned, having raised a number of disputes between citizens, local administration and central government. c)The future of this rubbish dump: for many years the local Municipalities along with the citizens demand the closure of it, and the construction of many smaller ones in several locations the greater Athens area, but no final decision has been made.

This pilot attracted mainly a young and educated part of this community, who used extensively the platform both for searching for and getting information and for posting opinions. However, the low computer literacy and educational level of this area and the fact that such a platform was a big innovation for this place were the main obstacles to the use of the platform by wider stakeholder groups. From an ease of use viewpoint, most of the respondents found the platform in general 'moderately easy' (52\%) (and only $22 \%$ 'very easy', while another $22 \%$ found it 'not that easy'); with respect to its particular capabilities most $(74 \%)$ found the forum 'very easy', while for the maps modules things are less clear: $50 \%$ found it 'moderately easy' and another 50\% 'very easy'. Concerning the functional usefulness, most of the respondents find that the maps modules helped them 'to a considerable extent' to get informed on the topics under discussion (48\%), to make better and more informed contributions to the forum discussion (59\%) and to learn new things on the topics under discussion from the postings of the others (55\%). As to the political usefulness, the majority believe that the outcome of this e-discussion will be higher than just getting informed: $34 \%$ believe that a 'consultation' level (provision of citizens' opinions to the local Municipality), and another 33\% an 'engagement' level (serious impact on municipality decisions) has been achieved, however only $15 \%$ believe that the particular visions and ideas they expressed in the forum discussion will be further considered. Finally the quantitative analysis provides evidence that most respondents found the discussion topics very important $(67 \%)$, and would be interested to return to use the platform in the future $(96 \%)$. In total, the respondents are satisfied with this e-participation pilot (56\% are 'satisfied' and $22 \%$ 'very satisfied').

The main conclusions of the qualitative discussion were that the system provided a good support to users through the provision of geographically and well organized content concerning important local Municipality decisions. However, it was mentioned that this pilot e-consultation based on such an advanced platform attracted mainly highly educated young citizens of this area, and to a much lower extent citizens of older ages and lower education and computer literacy, who are high important stakeholder groups, so their voice should be 'heard' by the local authorities. It was added that although there were efforts to promote the use of the platform, the main stakeholder groups were reluctant to adopt it, being quite sceptical towards the adoption of a new means of consultation: many did not believe that changing the means of debating the issue would lead to higher citizen empowerment and political influence. From the politicians' side it was noted that they did not believe in the platform very much as a decision making tool, but rather as a tool to understand voters' intentions towards the issues under discussion, especially before election time. 
Therefore we can identify a number of context factors which had a negative impact on this pilot: low computer literacy and familiarization, and also low trust to the local political system and low interest of the sponsoring local public authorities (Municipality of Ano Liossia).

\subsection{The Czech Pilot Application}

The Czech pilot application took place in the city of Brno and the towns of Kunstat and Letovice, and included electronic public deliberations on planned waste management infrastructures in this area. Because this topic was of interest mainly for people with high awareness on environmental issues, but of low interest for the 'general public' of this area (especially in a time of severe economic crisis), initially there were only few registrations; so it was necessary to organize many promotional campaigns, including e-mails to the registered users of a famous local environmental portal, which turned out to be successful. Finally this pilot attracted a satisfactory number young citizens, but of various educational levels, who used the platform extensively for searching for and getting information, and less for posting opinions. Concerning the ease of use, most of the respondents find 'very easy' both the platform in general (68\%), and its main modules, the forum $(66 \%)$ and the maps modules $(61 \%)$. With respect to the functional usefulness, most of the respondents find that the maps modules helped them 'to a large extent' (34\%) to get informed on the topics under discussion, to make better and more informed contributions to the forum discussion $(37 \%)$ and to learn new things from the postings of others $(46 \%)$, while another $27 \%, 24 \%$ and $22 \%$ respectively assess the assistance provided as 'considerable'. Also, as to political usefulness the majority believe that the outcome of this e-discussion will be higher than just getting better informed: $32 \%$ believe that a 'consultation' level is achieved (provision of citizens opinions to the local Municipalities), while 36\% expect an 'engagement' level (serious impact on Municipalities decisions), though only $37 \%$ believe that the particular visions and ideas they expressed in the forum discussion will be further considered. Most of the respondents (however belonging to citizens registered in environmental portals, having thus high awareness in environmental issues) find the discussion topics "very important' $(67 \%)$. In total, there is a high satisfaction of citizen participants by the experience of using the platform ( $47 \%$ are 'satisfied' and another $17 \%$ 'highly satisfied'), and most of them (71\%) would come back to use it in the future.

In the qualitative in-depth discussion that took place after the end of this pilot some interesting remarks were made concerning strengths and weaknesses of the platform. In particular, with respect to the ease of use of the platform the following strengths were identified:

- theme selection supported by GIS functionality is quite useful; also, it is possible to use GIS functionality, such as zoom, selection of area, etc., and this can be potentially improved by adding more GIS functionalities, such as overlapping, distances, etc.,

- content is available at the right place, it is at our disposal in a 'natural' way on the map, so it is not necessary to look for the content on various places,

- if offers the advantage of content classification, which makes the resulting conclusions from the it more clear and comprehensive, 
- advanced capabilities for setting access rights and moderation; also, it is possible to protect the portal against direct attack and spam attack, Also, at the same time the following weaknesses were mentioned:

- localization problems: every application, which is localized from another initial language, tends to bring some features not common in the new language; also, some language relations are not reflected naturally,

- the need for users registration: this is a problem, since in the Czech Republic it is very often not to trust the official authorities.

With respect to the usefulness the following strengths were identified:

- capability to share ideas among various levels of users, so it is possible that expert users can exchange opinions and ideas with non-specialist,

- capability to clearly see the geographical reference of topics and their context; the geographical connection of many important topics is not evident, but using digital maps this can be easily achieved,

- creation and sharing of content according to web 2.0 principles. Only the web 2.0 principles (numerous users create one extensive content) are capable of content creation in the desired quantity,

- the whole deliberation process on a particular public policy or decision is well documented and stored on digital media with all necessary information (documents provided by government organizations and citizens, and for each of them time, source, author, etc.); this makes it easy to create a well documented summary for decisions support (especially the help of content classification).

Also, at the same time the following weaknesses were mentioned:

- low quantity and quality of 'initial' reference content provided by government organizations can result in low interest and limited participation of citizens, since the success of this platform critically dependent on the content appended on the maps; only if the maps are interesting, and the documents appended on them are complete and updated, the portal can become interesting to the citizens,

- starting the discussion can be difficult, since it requires having at least a "critical mass' of participants and uploaded content (such a platform is characterized by strong ''network effects': more participants and uploaded content make it more attractive for additional citizens to participate and upload more content); for this reason many promotional campaigns were required in order to have a sufficient number of participants.

- also the complexity of the topics discussed can restricted the interest and participation of the public; the experts, on the other hand, usually have other actual channels of expression of their opinions, so the interest usually does not come from this target group, at least in the desired quantity.

By combining the findings of the quantitative and the qualitative analysis, we can identify a number of a number of context factors which had a negative impact on this pilot: the low level of computer usage skills in this area in most age groups with the exception of the youth (taking into account that historically there has been a lower level of computer usage skills in the Eastern European countries, this was an obstacle in attracting older age groups); the topic of the discussion, which was not of high interest to the general public (especially in a time of severe economic crisis); also, the fact that young citizens still do not feel politically empowered, as they declare that they do not know if the views they expressed in the forum discussions will be further 
considered. On the contrary the extensive promotional activities conducted by the organizers of this pilot, using appropriate channels (sending e-mails to the registered users of a famous local environmental portals), had a positive impact on this pilot.

\subsection{The UK Pilot Application}

The UK pilot application was implemented in the city of Blackburn and Darwen, which is located in the Northern Counties of England, covering an administrative area of $137 \mathrm{Km}^{2}$ and having a population of 137,470 persons. It was part of a wider consultation effort launched by the Unitary Authority of Blackburn with Darwen in 2009 in order to help shaping the future of this area. The central theme of this consultation, called Vision 2030, is how residents see this area now as well how they see it developing in the future. Its main questions are: i) Do you hope the borough will be centre of educational excellence with a world renowned university?, ii) Do you want it to be a hub of cutting edge businesses?, iii) Would you like it be viewed as the garden of the North West with award winning green spaces?, iv) Should our musical talent or food become famous nationwide? So this pilot included electronic public deliberations between citizens of this area about its future, both in general and on particular geographically referenced ideas and plans.

It should be noted that in this pilot the participants' group was more balanced from the age and education level perspective: we did not have predominantly young citizens, as in the pilots described in 5.1 and 5.2, but significant participants' percentages from various age groups (e.g. 35\% were between 31 and 40 years old, $29 \%$ between 41 and 50 years old and 13\% between 51 and 60 years old), and also from various educational levels (e.g. $45 \%$ had a university degree, while $34 \%$ had high school education). This reflects the high penetration of computers and Internet in various age and education level groups in UK. Concerning the ease of use most of the respondents found the platform in general 'very easy' (57\%), while with respect to its particular modules most found the maps modules 'moderately easy' (52\%) and the forum very easy (49\%). With respect to functional usefulness things are not so clear: the respondents believe that they have been benefited more from the postings of the other participants in the forum than from the map and the information appended on it. In particular, $50 \%$ of the respondents believe that the map and the information appended on it helped them to a 'considerable extent' (29\%) or 'large extent' $(21 \%)$ to get informed on the topic under discussion, while the remaining $50 \%$ can see only limited or no help at all. Similarly, $46 \%$ of the respondents believe that the map and the information appended on it helped them to a 'considerable extent' $(28 \%)$ or to a 'large extent' $(18 \%)$ to make better and more informed posting in the forum, while the remaining $54 \%$ can see only limited or no help at all. However, $60 \%$ believe that the postings of the other participants helped them to learn new things on the topic under discussion to a 'considerable extent' $(60 \%)$ or to a 'large extent' $(20 \%)$. The political usefulness was higher in comparison with the other pilots: it should be noted that $63 \%$ believe that their visions and ideas expressed in the forum will be further considered by the local government (and the remaining 37\% respond that they 'do not know', while nobody responds negatively), reflecting a higher level of trust to the local political system. With respect to the discussion topics most find them 'rather important' $(50 \%)$, which is understandable, since the future visions under discussion 
will not affect their everyday lives in the short term, though one third (23\%) find them 'very important'. In general, the respondents feel high level of satisfaction with this e-participation pilot, most of them being 'satisfied' (72\%) and the remaining 'highly satisfied' $(28 \%)$.

In the qualitative evaluation of the UK pilot the main points raised were that the platform and most of its modules were easy to use, though there were a few weak points identified with regard to navigation (e.g. were missing features for returning to the platform's start page, or for navigating through the different modules). The use of the forum in particular was found exceptionally easy for participating in the discussions held. However, it was remarked that the material initially appended on the map by the local authority was limited, and probably because of this citizens did not upload much their own documents (e.g. pictures, texts, etc.) either, and preferred mainly to enter posting sin the forum. This is compliant with the abovementioned result of the quantitative evaluation that citizens have been benefited more from the postings of the others in the forum than from the map and the information appended on it.

Based on the findings of the above quantitative and qualitative analyses we can identify two context factors which had a positive impact on this pilot: the high penetration of computers and Internet in various age and education level groups in UK (and not only in the young and educated citizens) and the higher trust to the local political system. Also, we can identify one factor which had a negative impact on the pilot: the limited material initially appended on the map by the local authority, which probably resulted in a reduced interest of the participants to upload their own content on it, who finally preferred to use the 'standard' and quite familiar to them forum functionalities, rather than the more advanced and innovative digital maps functionalities.

\subsection{The Cross-Border Pilot Application}

Also, a cross-border pilot was organized in cooperation between the Ministries of Environment of Czech Republic and Slovakia, taking advantage of the extensive collaboration between them after the split of Czechoslovakia in 1993. Both Ministries of the Environment are intensively working on the implementation of Framework Directive EU 2008/98/EC on waste management in order to develop their national legislation on this critical issue. For these reasons it was decided the main topic of this cross-country deliberation to be about waste management; also, it was decided to focus on the waste prevention, which is a key factor in any waste management strategy. Waste prevention is closely associated with improving manufacturing methods and influencing consumers to demand greener products and less packaging. In particular, this pilot included electronic discussions among young students who participated in the ENERSOL Conference about energy and environment.

The participants of this pilot were mainly young (56\% of them were 21 and 30 years old) and of high educational level (55\% were university degree holders and $17 \%$ postgraduate degree holders). With respect to ease of use they find 'very easy' the platform in general $(83 \%)$, and also its main modules, the map module $(78 \%)$ and the forum $(78 \%)$. As to the functional usefulness they believe that the map and the information appended on it helped them (50\% 'to a large extent' and $39 \%$ 'to a 
considerable extent') to get better informed on the topic under discussion and to make better and more informed postings about it in the forum. Also, they perceive high levels of political usefulness: most of the respondents $(72 \%)$ believe that an 'engagement' level of e-participation has been achieved (characterised by serious impact on decisions), while $61 \%$ of them believe that the particular visions and ideas they expressed in the forum discussion will be further considered. Also, most of them $(83 \%)$ find the discussion topics 'very important'. There was a high level of satisfaction in general from the use of the platform (45\% were 'satisfied' and $44 \%$ 'highly satisfied'). A common qualitative evaluation was conducted for this crossborder pilot and for the Czech pilot, as their user groups had several common citizens, so the remarks mentioned in 5.2 are valid for this pilot as well.

The conclusions drawn from the evaluation of these cross-border pilots were by far the most positive of all pilots. We can identify two main context factors which had a positive impact on this pilot: the high educational level and computer skills of the participants, and also their high interest in the discussion topics.

\subsection{The Dutch Pilot Application}

In the Dutch pilot the platform was used as an electronic support and facilitation in an already existing highly confrontational debate in Jmeer/Markermeer (located in the wider Amsterdam area) about the installation or not of 60.000 new houses, roadinfrastructure, bridges and support structure in a "green" area. This is a really difficult decision that local authorities have to make: on one hand it is necessary to expand the city of Amsterdam, and this area is the best alternative for this; however, on the other hand in this area there is a unique sweet water lake with European importance, protected by European directives on water management and Natura 2000 regimes. This pilot allowed us to investigate some important aspects of platform's usefulness for supporting and facilitating negotiations and consensus building on complex, critical and highly controversial government decisions and policies. As mentioned in section 5 the evaluation of this pilot focused on the political usefulness dimension, and was based on the responses of 21 representatives of the main conflicting stakeholders (e.g. chambers of commerce, national government, regional government, building companies, non-government organizations, local community activist organisations) in a questionnaire distributed to them, after having attended a detailed presentation of the platform. From the analysis of these responses the following quite interesting conclusions were drawn of the support this platform can provide in the main tasks of the decision making process:

- $88 \%$ of the respondents believe that the platform makes it 'easier', and another $6 \%$ 'much easier', to keep track of relevant discussions; so $92 \%$ in total perceive that it can support stakeholders in keeping track of the lengthy, complex and multiparticipant discussions on such spatial planning issues,

- $68 \%$ of the respondents find that the platform makes it 'easier', and another $13 \%$ 'much easier', to depict the complexity and interconnection of issues; so $81 \%$ in total perceive that it supports a better presentation, visualization and communication of the complex and highly interconnected issues and questions that spatial planning poses,

- 57\% believe that the platform makes it 'easier' to inform constituents (and all affected citizens in general) on the various issues and questions, 
- $67 \%$ believe that the platform 'makes clearer' the various legal constraints,

- $50 \%$ perceive that the platform improves 'to some extent', and $6 \%$ 'to a large extent', the transparency of the decision making processes; so $56 \%$ in total believe that such a system can have a positive impact on the transparency in this sensitive and multi-stakeholder area of spatial planning, which is critical democratic principle,

- and finally $62 \%$ believe that this platform can help them to represent and support better their interests.

In the qualitative discussion the above participants agreed that the presentation of legal constraints, development plans, and also stakeholders' proposals, ideas and visions of the various on digital maps can be very useful in such 'difficult' situations of complex, critical, multi-stakeholder and highly controversial decisions. Most participants maintained the position that decision making is however something much more complex than the information provision and communication enabled by this platform; so they did not think that the platform would solve the real decision dilemmas and conflict of interests. They did agree that more information provision, communication and transparency were relevant for a good result of the deliberation outcome.

\section{Discussion and Conclusions}

In the previous sections of this paper we have presented a systematic evaluation of an advanced e-participation platform based on digital maps and GIS tools, which was conducted through five pilot applications of it in five quite different national contexts (Greece, Czech Republic, Slovakia, UK and Netherlands) as part of the FEED project. The evaluation methodology was founded on the TAM, which was elaborated and adapted to the particular characteristics, capabilities and objectives of this platform; our main evaluation dimensions were usage, ease of use, functional usefulness, political usefulness and importance of discussion topic, which were assessed using both quantitative and qualitative techniques.

With respect to ease of use, the platform has been assessed in all pilots (with the only exception of the Dutch pilot, in which ease of use was not assessed, for the reasons explained in section 4) as very easy or moderately easy. This indicates that though GIS tools, as mentioned in section 2, initially were tools for specialists, if we design appropriately their functionality and user-interfaces they can be used by the general public as well (at least by citizens with sufficient general education and computer skills) as tools for a better e-participation, especially on geographically referenced issues. Also, the platform was found in all pilots to have high or considerable functional usefulness (again with the only exception of Dutch pilot, in which we focused on the political usefulness), as it enables the users to get better informed on the topic under discussion by accessing geographically organized information on digital maps, to upload on the map and in this way communicate effectively their own information, ideas and suggestions, and also to participate in electronic discussions. However, in three of the pilots (Greek, Czech and Crossborder) the political usefulness perceived by the users was lower, as most users do not think that the ideas and visions they expressed in the forum discussions will be further considered by the local authorities; this seems to reflect a low level of trust to the 
local political system, which can be an important obstacle to e-participation and all forms of public participation in general. However, in total citizen participants were satisfied by the experience of using the platform, and most of them would come back to use it in the future.

Finally, the most sophisticated Dutch pilot allowed us to investigate some important aspects of its political usefulness for supporting and facilitating negotiations and consensus building with respect to complex and highly controversial government decisions and policies. In particular, it was found that the platform enables a better presentation, visualization and communication of the complex and highly interconnected issues and questions that spatial planning poses, and assists stakeholders in keeping track of lengthy, complex and multi-participant discussions on spatial planning issues; at the same time it allows representatives of the various stakeholders to inform better their constituents and to represent and support better their interests. Also, such a platform makes more clear the various complex and very often overlapping legal constraints that exist in spatial planning, and contributes to higher transparency of the whole decision making processes.

In general, the use of digital maps and GIS tools seems to provide a well accepted and useful additional feature to the e-consultation process; the combination of digital maps/GIS with forum tools was proven to be both usable by the general public, requiring a reasonable and acceptable amount of effort, and also useful. The use of maps to pinpoint relevant data seems to be a well accepted practice by citizen users in order to broaden their understanding of complex local problems and spatial suggestions. Therefore we can definitely conclude that such an advanced platform can provide significant value in the area of e-participation, which however depends on some factors of the context in which it is used, such as computer literacy and familiarization, trust to the political system, interest of the sponsoring public authorities, importance of the topic under discussion and quality of reference information appended on the maps by public authorities.

\section{References}

1. Loukis, E., Peters, R., Charalabidis, Y., Passas, S., Tsitsanis, T.: Using e-Maps and Semantic Annotation for Improving Citizens' and Administrations' Interaction. In: Proceedings of the European and Mediterranean Conference on Information Systems 2009 (2009)

2. Loukis, E., Peters, R., Charalabidis, Y., Passas, S., Howe, C.: Enhancing Deliberation for the Formulation and Application of Public Policy on the Environment and Energy Using Federated Content, Ontologies and Maps. In: Proceedings of the First International Conference on e-Participation (2009)

3. Carver, S.: Participation and Geographical Information: a position paper. In: Proceedings of ESF-NSF Workshop on Access to Geographic Information and Participatory Approaches Using Geographic Information (2001)

4. Jankowski, P., Andrienko, N., Andrienko, G.L.: Map-Centered Exploratory Approach to Multiple Criteria Spatial Decision Making. International Journal of Geographical Information Science 15(2), 101-127 (2002)

5. Innes, J.E., Simpson, D.M.: Implementing GIS for Planning. Journal of the American Planning Association 59(2), 230-236 (2002) 
6. Talen, E.: Bottom-Up GIS: A New Tool for Individual and Group Expression in Participatory Planning. Journal of the American Planning Association 66(3), 279-294 (2000)

7. Ghose, R., Elwood, S.: Public Participation GIS and Local Political Context: Propositions and Research Directions. URISA Journal Special Issue on Access and Participatory Issues 15(2), 17-24 (2003)

8. Kingston, R.: Web Based PP GIS in the United Kingdom. In: Craig, et al. (eds.) Community Participation and Geographic Information Systems, pp. 101-112. Taylor \& Francis, Abington (2002)

9. Davis, F.D.: A Technology Acceptance Model for Empirically Testing New End-User Information Systems: Theory and Results, Cambridge. MIT Sloan School of Management, MA (1986)

10. Davis, F.D., Bagozzi, R.P., Warshaw, P.R.: User Acceptance of Computer Technology: A Comparison of Two Theoretical Models. Management Sciences 35(8), 982-1002 (1989)

11. Davis, F.D.: Perceived Usefulness, Perceived Ease of Use, and User Acceptance of Information Technology. MIS Quarterly 13(3), 319-339 (1989)

12. Schepers, J., Wetzels, M.: A meta-analysis of the technology acceptance model: Investigating subjective norm and moderation effects. Information \& Management 44(1), 90-103 (2007)

13. Holden, R.J., Karsh, B.T.: The Technology Acceptance Model: Its past and its future in health care. Journal of Biomedical Informatics 43(1), 159-172 (2010)

14. Organization for Economic Co-operation \& Development (OECD): Engaging Citizens Online for Better Policy-making. Policy Brief, Paris, France (2003)

15. Organization for Economic Co-operation \& Development (OECD): Promise and Problems of e-Democracy: Challenges of Online Citizen Engagement. Paris, France (2004) 